\title{
Somatostatin Receptor Types 1 and 2 in the Developing Mammalian Cochlea
}

\author{
Daniel Bodmer Yves Brand Vesna Radojevic \\ Department of Biomedicine and Clinic for Otorhinolaryngology, University Hospital Basel, Basel, Switzerland
}

\section{Key Words}

Central nervous system $\cdot$ Cochlea $\cdot$ Double-knockout mouse $\cdot$ Inner ear $\cdot$ Somatostatin $\cdot$ Somatostatin receptors

\begin{abstract}
The neuropeptide somatostatin (SST) exerts several important physiological actions in the adult central nervous system through interactions with membrane-bound receptors. Transient expression of SST and its receptors has been described in several brain areas during early ontogeny. It is therefore believed that SST may play a role in neural maturation. The present study provides the first evidence for the developmental expression of SST receptors in the mammalian cochlea, emphasizing their possible roles in cochlear maturation. In the developing mouse cochlea, cells immunoreactive to somatostatin receptor 1 (SSTR1) and somatostatin receptor 2 (SSTR2) were located in the embryonic cochlear duct on Kolliker's organ as early as embryonic day (E) 14 (E14). At E17, the expression of both receptors was high and already located at the hair cells and supporting cells along the length of the cochlear duct, which have become arranged into the characteristic pattern for the organ of Corti (OC) at this stage. At birth, SSTR1- and SSTR2-containing cells were only localized in the OC. In general, immunoreactivity for both receptors increased in the mouse cochlea from postnatal day (P) 0
\end{abstract}

(P0) to P10; the majority of immunostained cells were inner hair cells, outer hair cells, and supporting cells. Finally, a peak in the mRNA and protein expression of both receptors is present near the time when they respond to physiological hearing (i.e., hearing of airborne sound) at P14. At P21, SSTR1 and SSTR2 levels decrease dramatically. A similar developmental pattern was observed for SSTR1 and SSTR2 mRNA, suggesting that the expression of the SSTR1 and SSTR2 genes is controlled at the transcriptional level throughout development. In addition, we observed reduced levels of phospho-Akt and total Akt in SSTR1 knockout and SSTR1/ SSTR2 double-knockout mice compared with wild-type mice. We know from previous studies that Akt is involved in hair cell survival. Taken together, the dynamic nature of SSTR1 and SSTR2 expression at a time of major developmental changes in the cochlea suggests that SSTR1 and SSTR2 (and possibly other members of this family) are involved in the maturation of the mammalian cochlea.

Copyright $\odot 2012$ S. Karger AG, Basel

\section{Introduction}

Hearing loss is a global health problem with a profound socioeconomic impact. Acquired hearing loss is mainly a modern disorder caused by (among other things)

\section{KARGER \\ Fax +4161306 1234 \\ E-Mail karger@karger.ch}

www.karger.com
(C) 2012 S. Karger AG, Basel

$0378-5866 / 12 / 0344-0342 \$ 38.00 / 0$

Accessible online at:

www.karger.com/dne
Dr. Daniel Bodmer

Klinik für Ohren-, Nasen-, Halskrankheiten, University Hospital Basel Petersgraben 4

$\mathrm{CH}-4031$ Basel (Switzerland)

Tel. +41 61328 7603, E-Mail dbodmer@uhbs.ch 
human-made noise and modern drugs. These factors, combined with increasing lifespan, have exposed a deficit in cochlear self-regeneration that had been irrelevant throughout most of mammalian evolution. The mammalian inner ear is an unusually complex organ that contains both vestibular and auditory parts. The vestibular sensory organs are necessary for the maintenance of normal balance. The coiled cochlea which contains the organ of Corti (OC) consists of four parallel rows of sensory hair cells (HCs) along the longitudinal axis of the spiraled cochlea. The first row of HCs from the center (or medial side) of the cochlea is known as inner hair cells (IHCs). The remaining three rows of HCs toward the periphery (or lateral side) of the cochlea are known as outer HCs. Invariably, HCs are separated from each other by several types of morphologically distinct nonsensory supporting cells, including Deiter's cells (DC), Claudius cells, Boettcher cells, and pillar cells (PiC). Supporting cells share a common progenitor with HCs [1], and are a morphologically diverse population of epithelial cells that surround HCs and provide structural and functional support. In mice, the cochlear duct arises as a ventral evagination of the developing otocyst beginning at approximately embryonic day (E) 11 (E11) [2]. The duct itself is comprised of pseudostratified epithelial cells derived from the otic placode. By E12, the chirality of the growing duct becomes obvious as it begins to coil. During development, the precursor cells give rise to both sensory $\mathrm{HCs}$ and the formation of supporting cells. These precursor cells, which transiently form Kolliker's organ (KlO) in the OC, exit the cell cycle at approximately E14. By E17, HCs and supporting cells have become arrayed along the length of the cochlear duct. Gross anatomical changes of the inner ear have been correlated with the appearance of each sensory organ. In turn, the appearance of each organ has been identified by the observation of specific gene expression in sensory regions before histological differentiation. The Notch signaling pathway has multiple roles during inner ear development $[3,4]$. Notch signaling activates the transcription of Hes5, a homologue of Drosophila hairy and enhancer of split proteins, which encodes a basic helix-loop-helix transcriptional repressor. Previous studies have shown that Hes 5 is expressed in the cochlea during embryonic development [5-7].

Somatostatin (SST), a regulatory peptide with two bioactive forms, SST-14 and SST-28, is produced in neuroendocrine cells in the brain and periphery and acts on a wide array of tissue targets to modulate neurotransmission, cell secretion, and cell proliferation $[8,9]$. The actions of SST are mediated by a family of G protein-cou-

Somatostatin Receptors 1 and 2 in the Developing Cochlea pled receptors with five subtypes (SST receptors 1-5, SSTR1-5) encoded by separate genes $[8,10]$. SSTR couple to the voltage-dependent $\mathrm{Ca}^{2+}$ channels and mediate the inhibition of $\mathrm{Ca}^{2+}$ conductance by SST. Cloned SSTR2 has been reported to inhibit $\mathrm{Ca}^{2+}$ conductance when expressed in RINm5F cells [11]. SSTR have also been reported to couple to $\mathrm{Ca}^{2+}$-dependent $\mathrm{K}^{+}$channels and mediate increases in $\mathrm{K}^{+}$conductance [12]. The modulation of ionic conductance may be an underlying mechanism by which SST inhibits neuronal cell firing and reduces neurotransmitters and hormone secretion.

Studies over the last few years in mice show that SST and its receptors appear to play an important role in cell death. In a retina ischemia model, activation of the SSTR2 protected retinal neurons from damage [13]. In the pituitary tumor cells the octreotid, a SST analogue, mediates its antiproliferative action by altering phosphatidylinositol-3-kinase (PI3K)-Akt signaling [14]. Also in neuroendocrine tumors octreotid decreases PI3K-Akt signaling [15]. Dying HCs after ototoxic and acoustic trauma exhibit apoptotic morphology, suggesting that apoptosis is involved in HC death. Inhibition of apoptotic HC death can be manipulated by blocking of caspase family and the MAPK-JNK pathway [16]. We have demonstrated recently that the PI3K-Akt pathway is involved in NF- $\kappa \mathrm{B}$-dependent $\mathrm{HC}$ survival. Most importantly, we found improved HC survival in SST-treated OC explants that had been exposed to gentamicin compared to those explants exposed to gentamicin alone [17]. Therefore, it might be possible that SST also exerts its effect on HCs through the PI3K-Akt survival pathway.

SST is a potential candidate for influencing early neuronal development, since the neuropeptide is transiently expressed in several neuronal systems. A variety of studies support a developmental role for SST by documenting its early onset, transient expression, and morphogenetic effects $[18,19]$. Transient expression of SST protein or mRNA has been described in the cerebellum [20], the cerebral cortex [21], and in sensory systems, including the somatosensory, visual [22], and auditory systems [23]. Recent studies have shown that SST exerts some regulatory effects during neuronal maturation, as it has been reported that SST enhances neurite outgrowth in cultured cerebellar neurons [24].

In prenatal brain neurons, SST and its receptors are expressed early and transiently; however, little is known about their function during early mammalian cochlear development. Our previous study demonstrated that SSTR1 and SSTR2 mRNA and protein were expressed in the adult mouse cochlea, and were localized in the IHC, 
outer hair cells (OHC), and supporting cells of the OC [25]. SSTR 3, 4, and 5 have not been shown to be essential for the function of SST [10]. Therefore, we focused our attention on the distributions of SSTR1 and SSTR2. Our examinations focused on E14, E17, and the first 3 postnatal weeks, when important steps of cochlear and synapse maturation occur and hearing begins [26-28]. In this study, we investigated the expression patterns of SSTR1 and SSTR2 in the cochlea of the developing mouse, and correlated it with developmental events. The expression levels of SSTR1 and SSTR2 in mouse cochlea between E14 and postnatal day (P) 21 (P21) were assessed at the mRNA and protein levels. Morphological studies were also conducted. In this study, SSTR1/SSTR2 double-knockout (DKO) mice were generated to determine the importance of these receptors because there are compensatory effects in the single knockouts $(\mathrm{KO})$ and the phenotype of the DKO has not been characterized previously.

Finally, we analyzed the expression levels of phosphoAkt and total Akt in wild-type (WT), SSTR1 KO, and SSTR1/SSTR2 DKO mice.

\section{Material and Methods}

\section{Animals}

Experiments were performed on mouse cochleae from WT C57BL/6 mice of both sexes. The expression of both receptors was detected in mice at embryonic stages $(n=10$ per embryonic day for mRNA isolation; $\mathrm{n}=10$ per embryonic day for protein isolation; $\mathrm{n}=4$ per embryonic day for immunohistochemistry). The patterns of SSTR1 and SSTR2 expression were also observed at postnatal ages $(\mathrm{n}=10$ per postnatal day for mRNA isolation; $\mathrm{n}=$ 10 per postnatal day for protein isolation). Immunohistochemistry was performed on 4 mice per postnatal day). The procedures used to generate SSTR1 ${ }^{-1-}$ (homozygous SSTR1 KO)/C57BL6J mice [29] and SSTR2 ${ }^{-/}$(homozygous SSTR2 KO)/C57BL6J mice have been described previously [30]. SSTR1 KO mice were crossed with SSTR2 KO mice to produce DKO mice. Age-matched WT mice were produced from the C57BL6J mice that were used to stabilize the genetic backgrounds of the SSTR1 KO and SSTR2 KO mice. The SSTR1/SSTR2 DKO showed no apparent abnormalities. They reproduced normally with a litter size of 6-10 animals. When homozygous animals were compared with their WT littermates no obvious abnormalities were detected. No differences in the body weight of adult animals were observed. Upon dissection of adult animals internal organs were found to be of normal size and shape. We tested the hearing of DKO mice using brainstem electric-response audiometry. We tested age-matched DKO, WT, and SST1 KO mice ( $\mathrm{n}=15$ mice per group) 3 times at approximately 3 months of age. Compared with WT and SST1 KO mice, SSTR1/SSTR2 DKO mice exhibited hearing impairment [unpubl. observation].

Animal care and use were conducted in conformity with the European Communities Council Directive of 24 November 1986
(86/609/EEC), and were reviewed and permitted by the Kantonales Veterinäramt, Basel, Switzerland.

\section{RNA Extraction}

The OCs from WT mouse pups aged E14-P21 were later placed separately in RNA (Qiagen, Hombrechtikon, Switzerland). RNA isolation of the brains and the inner ear components was performed using the RNAeasy Minikit (Qiagen) and employing an Ultra-Turrax T8 tissue homogenizer (IKA-Werke, Staufen, Germany) according to the manufacturer's instructions, including DNAse treatment. The quantity and quality of isolated RNA were determined with NanoDrop ND 1000 (NanoDrop Technologies, Wilmington, Del., USA). The $260 / 280-\mathrm{nm}$ ratio of all samples was between 1.8 and 2.1 .

\section{Reverse Transcription Polymerase Chain Reaction}

Total RNA (500 ng) was reverse transcribed into cDNA with the first-strand cDNA synthesis kit for reverse transcription polymerase chain reaction (RT-PCR; Roche Applied Bioscience, Rotkreuz, Switzerland) according to the supplier's instructions. PCR was performed using the PCR Master Mix (Roche Applied Bioscience) with primers specific for SSTR1 and SSTR2. $\beta$-Actin primers were used as a positive control for cDNA synthesis. Primers were designed to cross at least one exon junction for the specific amplification of cDNA and to recognize genomic DNA contamination. The primer sequences were: SSTR1 forward (fwd): $5^{\prime}$ CAGGGTAGCGCCATTCTCATC-3', SSTR1 reverse (rev): 5'AGCGTGGAAGTGACCAGAAAG-3', SSTR2 fwd: 5'-CGCATGGTGTCCATCGTAGT-3', SSTR2 rev: 5'-GGATTGTGAATTGTCTGCCTTGA-3', $\beta$-actin fwd: 5'-ACGGTCAGGTCATCACTATCGGCA-3', and $\beta$-actin rev: 5'-ATCCTGTCAGCAATGCCTGGGT-3' (Microsynth, St. Gallen, Switzerland).

PCR reactions were performed in the Eppendorf Mastercycler (Eppendorf, Hamburg, Germany). For SSTR1 and SSTR2, the initial denaturing step $\left(94^{\circ} \mathrm{C}\right.$ for $\left.30 \mathrm{~s}\right)$ was followed by 30 PCR cycles, each consisting of denaturation at $94^{\circ} \mathrm{C}$ for $15 \mathrm{~s}$, annealing at $60^{\circ} \mathrm{C}$ for $30 \mathrm{~s}$, and extension at $72^{\circ} \mathrm{C}$ for $15 \mathrm{~s}$. PCR was completed with a final extension step at $72^{\circ} \mathrm{C}$ for $3 \mathrm{~min}$. $\beta$-Actin was subjected to 30 PCR cycles, each consisting of denaturation at $94^{\circ} \mathrm{C}$ for $30 \mathrm{~s}$, annealing at $58^{\circ} \mathrm{C}$ for $45 \mathrm{~s}$, and extension at $72^{\circ} \mathrm{C}$ for 90 s. PCR was completed with a final extension step at $72^{\circ}$ for $5 \mathrm{~min}$. The PCR products were stained with SybrGreen I (Molecular Probes, Eugene, Oreg., USA), separated by electrophoresis on a $2 \%$ agarose gel, and visualized under ultraviolet light. Omission of RT-PCR was used as the no-template control.

\section{Real-Time PCR}

Total RNA (500 ng) was reverse transcribed into cDNA using the First Strand cDNA synthesis kit (Roche Applied Biosciences) according to the manufacturer's instructions. The reaction took place in an ABI Prism 7900HT Sequence Detection System (Applied Biosystems) using a Fast Start Universal SYBR Green Master (Rox) (Roche Applied Biosciences, Foster City, Calif., USA). The primer sequences were: SSTR1 fwd: 5'-CAGGTTTAAAGAACTGGCAAGC-3', SSTR1 rev: 5'-ATTAATAAGCGGCACCATCG3', SSTR2 fwd: 5'-TCTTTGCTTGGTCAAGGTGA-3', and SSTR2 rev: 5'-TCCTGCTTACTGTCGCTCCT-3' (Microsynth). Each reaction contained $300 \mathrm{nM}$ of primer. The cycling parameters were $10 \mathrm{~min}$ at $95^{\circ} \mathrm{C}$, followed by 40 cycles of $95^{\circ} \mathrm{C}$ for $15 \mathrm{~s}$ and $60^{\circ} \mathrm{C}$ for $60 \mathrm{~s}$. We calculated relative quantities of specifically amplified 
cDNA using the comparative threshold cycle method. GAPDH was used as an endogenous reference (Microsynth). Template-free and reverse-transcription-free controls ensured that nonspecific amplification and DNA contamination could be excluded.

\section{Preparation of Paraffin Cochlear Sections}

Mice were killed with an overdose of sodium pentobarbital $(100 \mathrm{mg} / \mathrm{kg})$ and transcardially perfused with $50 \mathrm{ml}$ of phosphatebuffered $4 \%$ paraformaldehyde $\left(\mathrm{pH} 7.4\right.$, at $\left.4^{\circ} \mathrm{C}\right)$. The inner ear was carefully removed. Decalcification was carried out in a light-protected flask for 10 days in a solution of $120 \mathrm{mM}$ EDTA (Merck, Whitehouse Station, N.J., USA) in distilled water ( $\mathrm{pH}$ 6.8). After decalcification, cochleae were prepared for paraffin embedding. Briefly, cochleae were dehydrated in graded ethanol solutions (at $70,80,95 \%$, and $3 \times 100 \%$, each for $1 \mathrm{~h} ; 3 \times$ xylol for $1 \mathrm{~h} ; 2 \times$ paraplast at $-60^{\circ} \mathrm{C}$ for $1 \mathrm{~h}$, and paraplast at $-60^{\circ} \mathrm{C}$ for $10 \mathrm{~h}$ ), and embedded in paraffin at $56^{\circ} \mathrm{C}$.

\section{Histology and Immunocytochemistry}

For histological evaluation, cochlear sections of $10 \mu \mathrm{m}$ thickness were cut on a Leitz microtome and mounted on Superfrost plus slides (Menzel, Braunschweig, Germany). Sections were deparaffinized, rehydrated, washed in PBS for $5 \mathrm{~min}$, and subjected to immunohistochemistry. For histological evaluation of the brain, coronal sections of $30-\mathrm{mm}$ thickness were collected and mounted on Superfrost Plus slides (Menzel) and dried at room temperature. Microtome sections of mouse cochlea were incubated for $1 \mathrm{~h}$ at room temperature in blocking solution (PBS-T) containing 5\% Triton $\mathrm{X}-100(\mathrm{pH} 8)$ and $3 \%$ normal goat serum (NGS). The sections were incubated with primary antibody diluted in PBS-T with $1 \%$ NGS overnight at $4^{\circ} \mathrm{C}$. The following primary antibodies were used: rabbit polyclonal anti-SSTR1 and anti-SSTR2 antibodies (1: 400, Gramsch Laboratories, Schwabhausen, Germany) and mouse monoclonal anti-Hes5 antibody (1:300, AbCam, Cambridge, UK). After 3 washes in PBS-T, the sections were incubated for $1 \mathrm{~h}$ at room temperature with the appropriate secondary antibodies (1:250, Alexa-conjugated, Molecular Probes, LuBioScience, Lucerne, Switzerland) diluted in PBS-T with $1 \%$ NGS for $2 \mathrm{~h}$ at room temperature. After washing in PBS, the sections were counterstained with DAPI and mounted on glass slides with Mowiol.

Slices were visualized on an Olympus AX-70 microscope equipped with a spot digital camera. Recorded images were adjusted for brightness and contrast using Image-Pro Plus and Photoshop image processing software.

\section{Confocal Microscopy}

The paraffin sections were analyzed using a confocal laser scanning microscope (TCS5D, Leica Microsystems, Mannheim, Germany) equipped with multiple laser line excitation $(405,458$, 488, 514, 561, and $633 \mathrm{~nm}$ ), acustooptical devices (AOTF and AOBF modules), and operated in the simultaneous acquisition mode. Images were recorded with an apochromatic $60 \times / \mathrm{nA} 1.4$ objective lens. Image stacks of 15-25 optical layers were sampled according to the Nyquist theorem. Subsequently, the stacks of images were displayed using the Imaris software package (Bitplane AG, Zürich, Switzerland).

\section{Western Blotting}

Animals were decapitated and cochleae were carefully microdissected in ice-cold PBS. The OC was separated from the spiral ganglion and the stria vascularis. Brain extract was used as a positive control. Explants were homogenized in CelLytic buffer containing protease inhibitor cocktail (Sigma-Aldrich, St. Louis, Mo., USA) and centrifuged. Supernatants were aspirated and placed in a new tube. Protein concentration was determined using the BCA Protein Assay Reagent kit (Pierce, Rockford, Ill., USA) according to the manufacturer's instructions. Lysates were mixed with Laemmli sample buffer and heated at $95^{\circ} \mathrm{C}$ for $5 \mathrm{~min}$. A $20-\mu \mathrm{g}$ sample of each lysate was resolved on a $10 \%$ SDS-PAGE gel and blotted onto a polyvinylidene fluoride membrane. The nonspecific sites of the transferred proteins were blocked with blocking solution (Roche, Switzerland) diluted (1:100) in PBS-T (1.54 mM $\mathrm{KH}_{2} \mathrm{PO}_{4} ; 155.17 \mathrm{mM} \mathrm{NaCl} ; 2.71 \mathrm{mM} \mathrm{Na} \mathrm{HPO}_{4} \cdot 7 \mathrm{H}_{2} \mathrm{O}$, pH 7.2; $0.1 \%$ Tween 20 ) for $1 \mathrm{~h}$ at room temperature. The membrane was washed with PBS-T $(3 \times 10 \mathrm{~min})$ and then incubated with primary antibodies in TBS. The following primary antibodies were used: rabbit polyclonal anti-SSTR1 and anti-SSTR2 (1:1,000, Abcam, UK), rabbit polyclonal anti-Akt (1:1,000, Cell Signaling, Switzerland), rabbit polyclonal anti-phospho-Akt (1:1,000, Cell Signaling, Switzerland), and mouse monoclonal anti- $\beta$-actin (1:5,000, Santa Cruz Biotech, Santa Cruz, Calif., USA). The membranes were incubated with the primary antibodies overnight at $4{ }^{\circ} \mathrm{C}$. Next, the blots were incubated with monoclonal anti-rabbit peroxidase-conjugated secondary antibody (1:80,000; Sigma-Aldrich, St. Gallen, Switzerland) and anti-mouse peroxidase-conjugated secondary antibody (1: 200,000; Sigma-Aldrich).

The blots were washed with PBS-T $(3 \times 10 \mathrm{~min})$ and incubated with appropriate peroxidase-conjugated secondary antibody for $1 \mathrm{~h}$ at room temperature (Roche, Basel, Switzerland). After washing, bands were visualized using BM chemiluminescence developmental solution (Roche). The immunopositive bands were visualized by autoradiograpy. Serial exposures were made to radiographic film (Hyperfilm ECL; Amersham Biosciences, Little Chalfont, UK).

\section{Statistical Analysis and Software}

Statistical analysis was performed using Student's t test for unpaired samples; means were considered statistically significant when the $\mathrm{p}$ value was $<0.05$. The Origin computer program ( $\mathrm{Mi}-$ crocal Software, Inc., Northampton, Mass., USA) was used to generate graphs and for statistical analysis.

\section{Results}

\section{Expression of SSTR 1 and SSTR $2 \mathrm{mRNA}$ in the}

\section{Embryonic and Postnatal Mouse Cochlea}

RT-PCR and the use of specific primer sets indicated that SSTR1 and SSTR2 mRNA were detected in the OCs from WT mice at E14, E17, and postnatal day (P) 0, P5, $\mathrm{P} 10, \mathrm{P} 14$, and P21. A single band of the correct size was observed for every tissue, indicating the presence of both SSTR1 and SSTR2 mRNA in the OC throughout postnatal development. The amplification of $\beta$-actin confirmed that cDNA synthesis was successful (fig. 1). We performed real-time PCR to determine the quantitative gene 
Fig. 1. Gene expression of SSTR1 and SSTR2 in OC explants at different embryonic and postnatal ages. SSTR1 and SSTR2 mRNA were detected in the OC of WT mice by RT-PCR and the use of specific primer sets at E14 and E17, as well as at $\mathrm{P} 0$, P5, P10, P14, and P21. Brain (Br) RNA was used as a positive control. Omission of RTPCR was used as the no-template control (ntc). $\beta$-Actin was used to control cDNA synthesis. $\mathrm{M}=$ Molecular weight marker.

Fig. 2. Cochlear expression of SSTR1 and SSTR2 genes in OC explants at E14 and E17. The relative distribution of SSTR1 and SSTR2 mRNA expression in OC tissue from WT mice of different embryonic ages was quantified by real-time PCR. GAPDH was used as an endogenous control. Results are expressed as the mean $( \pm \mathrm{SE})$.


expression of SSTR1 and SSTR2 at E14 and E17. Cochlear expression of both genes was significantly increased at E17 compared with E14 (fig. 2).

\section{Embryonic Expression of SSTR1 and SSTR2}

SSTR1 and SSTR2 were not detected in the embryonic cochlea before E14 (data not shown). At E14, both SSTR1 and SSTR2 appeared to be associated with the thickened epithelial cells located in KlO (fig. 3). SSTR1 and SSTR2 immunoreactivity was clearly detected at E17 in the region of HCs and supporting cells along the length of the cochlear duct, which in this stage have become arranged into the characteristic pattern for the OC (fig. 4). Antibody against Hes5 was used as a cochlear developmental marker, and was colocalized with SSTR2 in the embryonic OC at E17 (fig. 4g).
Postnatal SSTR1 and SSTR2 Expression (P0-P21)

At birth, within the OC, SSTR1 and SSTR2 labeling included the IHC, OHC, and DC, extending laterally to include the Claudius cells (fig. $5 \mathrm{~d}, \mathrm{e}$ ). Cochlear tissue was largely differentiated by P5 (fig. 5f, g). During this period, the immunolabeling of the examined SSTR1 and SSTR2 continued to differentiate in different OC structures. At P10, the levels of both SSTR1 and SSTR2 were decreased in the IHC, but were high in the OHC, DC, and PiC (fig. 6a, b). At P14, the strongest expression of both receptors was observed in the IHC, OHC, and DC in the OC (fig. 6c, d). By P21, expression of both receptors was less strong in the IHC and $\mathrm{OHC}$, and absent in the PiC (fig. $6 e, f)$. 

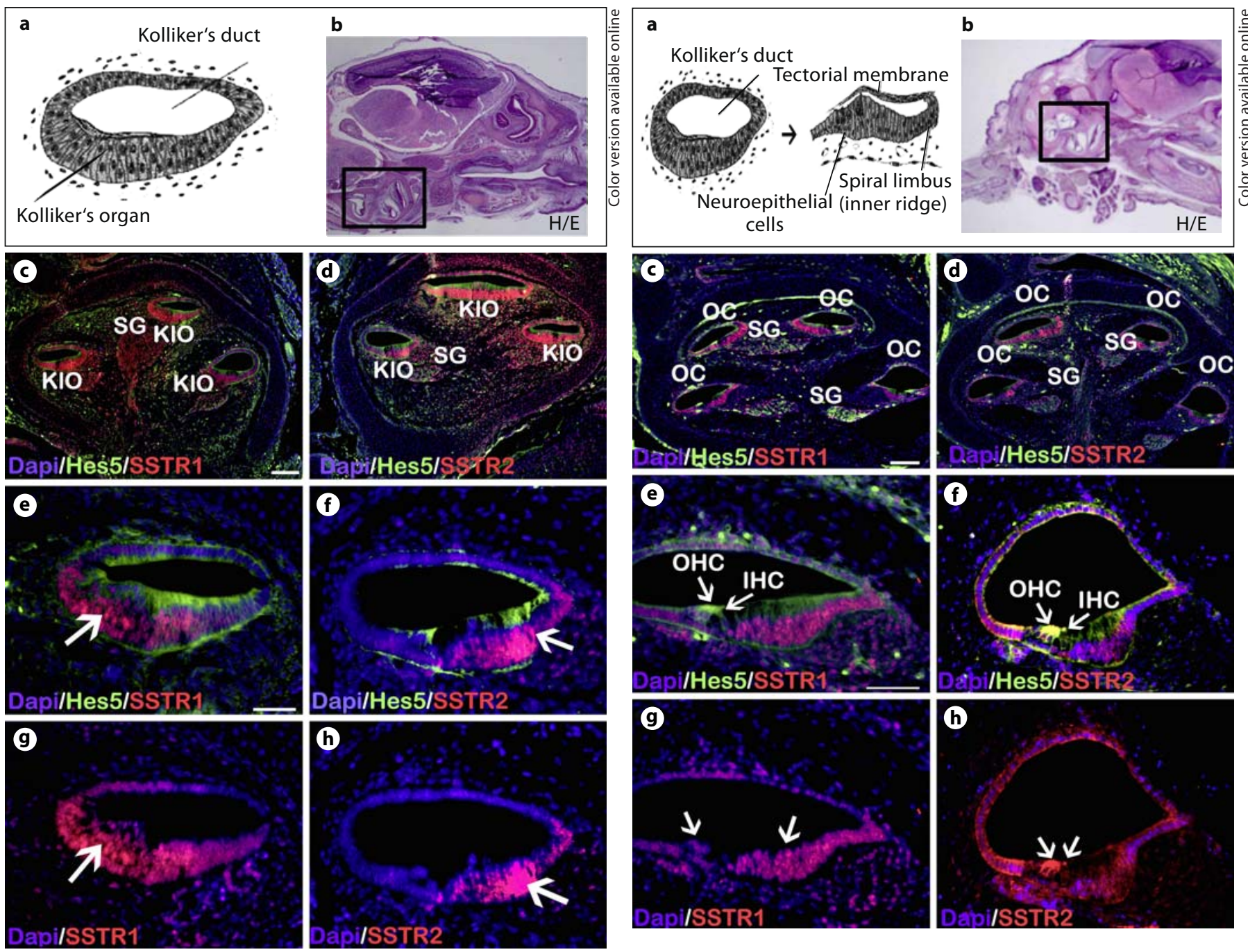

Fig. 3. Immunolabeling of SSTR1 and SSTR2 in the mouse cochlea at E14. Cell nuclei are in blue, SSTR1 and SSTR2 are in red, and transcription factor Hes5 is in green. a The diagram of embryonic OC source: http://syllabus.med.unc.edu. b A light microscopy image of an E14 mouse head (sagittal section) stained with hematoxylin/eosin. The box indicates the cochlea. c, d In these immunofluorescence images, SSTR1 and SSTR2 can be observed in $\mathrm{KlO}$ and the spiral ganglion (SG). e-h In these immunofluorescence images, SSTR1 and SSTR2 can be observed in epithelial cells located in the embryonic cochlear duct. Transcription factor Hes5 staining was used as a marker for the embryonic cochlea. Scale bar $=50 \mu \mathrm{m}$.

As shown in figure 7, the developmental patterns of SSTR1 and SSTR2 proteins share some similarities, with increased protein expression in the first 2 postnatal weeks followed by a moderate decrease in expression around the time of airborne hearing.

Fig. 4. Immunolabeling of SSTR1 and SSTR2 in the mouse cochlea at E17. Cell nuclei are in blue, SSTR1 and SSTR2 are in red, and transcription factor Hes5 is in green. a The diagram of embryonic OC source: http://syllabus.med.unc.edu. b A light microscopy image of an E1 mouse head (sagittal section) stained with hematoxylin/eosin. The box indicates the cochlea. c, d In these immunofluorescence images, SSTR1 and SSTR2 can be observed in the OC and spiral ganglion (SG). e-h In these immunofluorescence images, SSTR1 and SSTR2 can be observed in the OHC and IHC. Weak labeling was observed in the supporting cells of the embryonic cochlear duct. Transcription factor Hes5 staining was used as a marker for the embryonic cochlea. Scale bar $=50 \mu \mathrm{m}$.

\section{Effect of Knocking out SSTR1 and SSTR2 in DKO}

Mice

SSTR1 and SSTR 2 mRNA were detected in the brain and OC WT mice by RT-PCR using specific primer sets. SSTR1 and SSTR2 mRNA were not detected in brain

Somatostatin Receptors 1 and 2 in the 

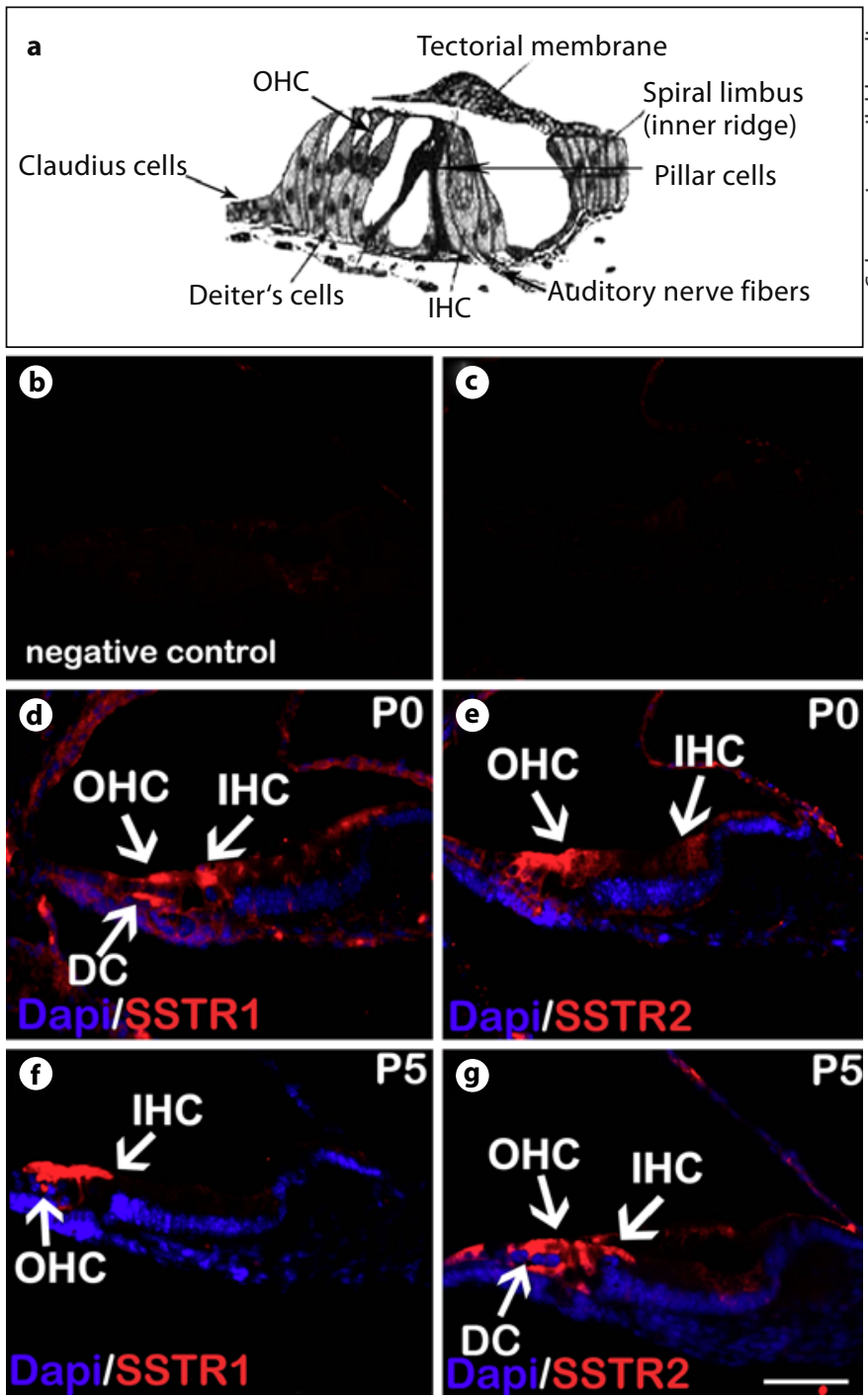

Fig. 5. The protein expression pattern of SSTR1 and SSTR2 in the mouse cochlea from P0 through P5. Cell nuclei are in blue, and SSTR1 and SSTR2 are in red. a The diagram of OC source: http:// syllabus.med.unc.edu. b, c Negative controls. d, e At P0, SSTR1 and SSTR2 can be observed in the OHC, the IHC, and the membrane of DC.f, $\mathbf{g}$ At P5, both receptors can be detected in the OHC, the IHC, DC, and the outer and inner PiC. Scale bar $=50 \mu \mathrm{m}(\mathbf{a}-\mathbf{g})$.

samples from DKO mice (fig. 8a). Using Western blotting, we were unable to detect bands corresponding to SSTR1 and SSTR2 in the protein lysate from DKO cochlea (fig. 8b). Immunohistochemistry was performed to locate SSTR1 and SSTR2 in the adult SSTR1/SSTR2 DKO mouse cochlea. No SSTR1 or SSTR2 staining was observed in cochlea from DKO mice, indicating the complete absence of both proteins from the cochlea of this
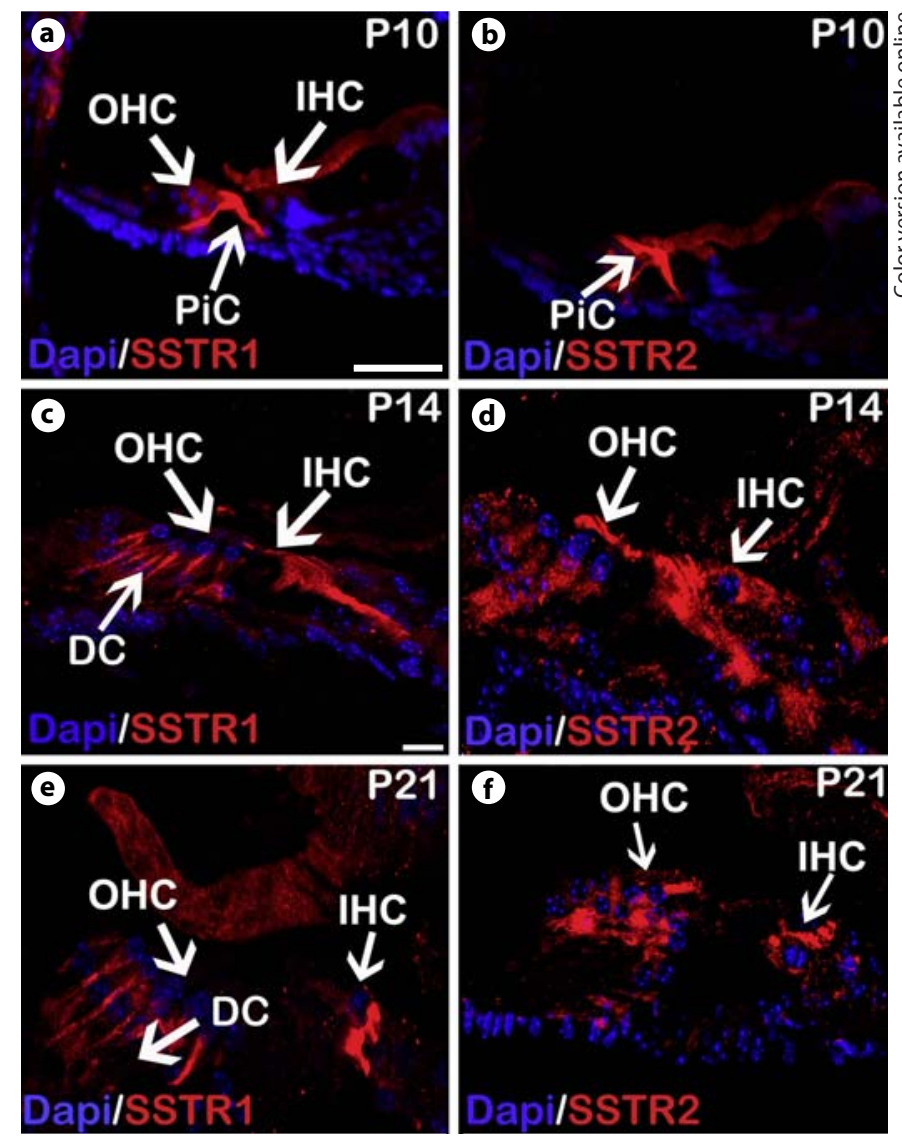

Fig. 6. The protein expression pattern of SSTR1 and SSTR2 in the mouse cochlea prior to the onset of hearing (P10-P21). Cell nuclei are in blue, and SSTR1 and SSTR2 are in red. a, b At P10, SSTR1 and SSTR2 are strongly expressed in the supporting cells as PiC. The OHC and IHC were also positively labeled. c, d At P14, both receptors can be detected in the $\mathrm{OHC}$, the IHC, and the membrane of DC. e, $\mathbf{f}$ At P21, the expression of both receptors had decreased relative to $\mathrm{P} 14$, and labeling was detected in the $\mathrm{OHC}$, the IHC, and the membrane of DC. Immunofluorescence microscopy images: scale bar $=50 \mu \mathrm{m}(\mathbf{a}, \mathbf{b})$. Confocal microscopy images: scale bar $=25 \mu \mathrm{m}(\mathbf{c}-\mathbf{f})$.

mouse model and confirming the specificity of the antibody used (fig. 8c).

Total Akt and Phosphorylated Akt in Cochlea from WT, SSTR1 KO, and DKO Mice

The expression of phospho-Akt and total Akt was assessed in the brain and in OC explants from WT, SSTR1 $\mathrm{KO}$, and DKO mice. We observed reduced levels of both 

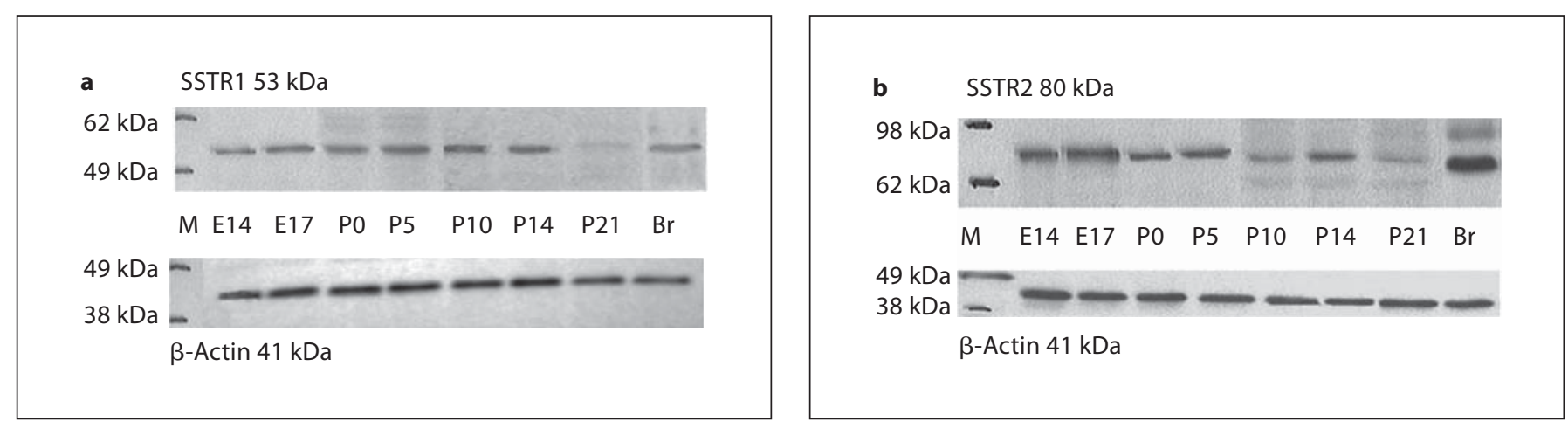

Fig. 7. Detection of SSTR1 and SSTR2 in the mammalian cochlea by Western blotting. Western blotting reveals that SSTR1 and SSTR2 can be detected in protein extracts from embryonic and postnatal OC. Brain extract was used as a positive control, and $\beta$-actin levels were used as loading controls. SSTR 1 and SSTR 2 contain a number of glycosylation sites (SwissProt), which may explain their migration at a higher molecular weight than predicted. $\mathrm{M}=$ Molecular weight marker.
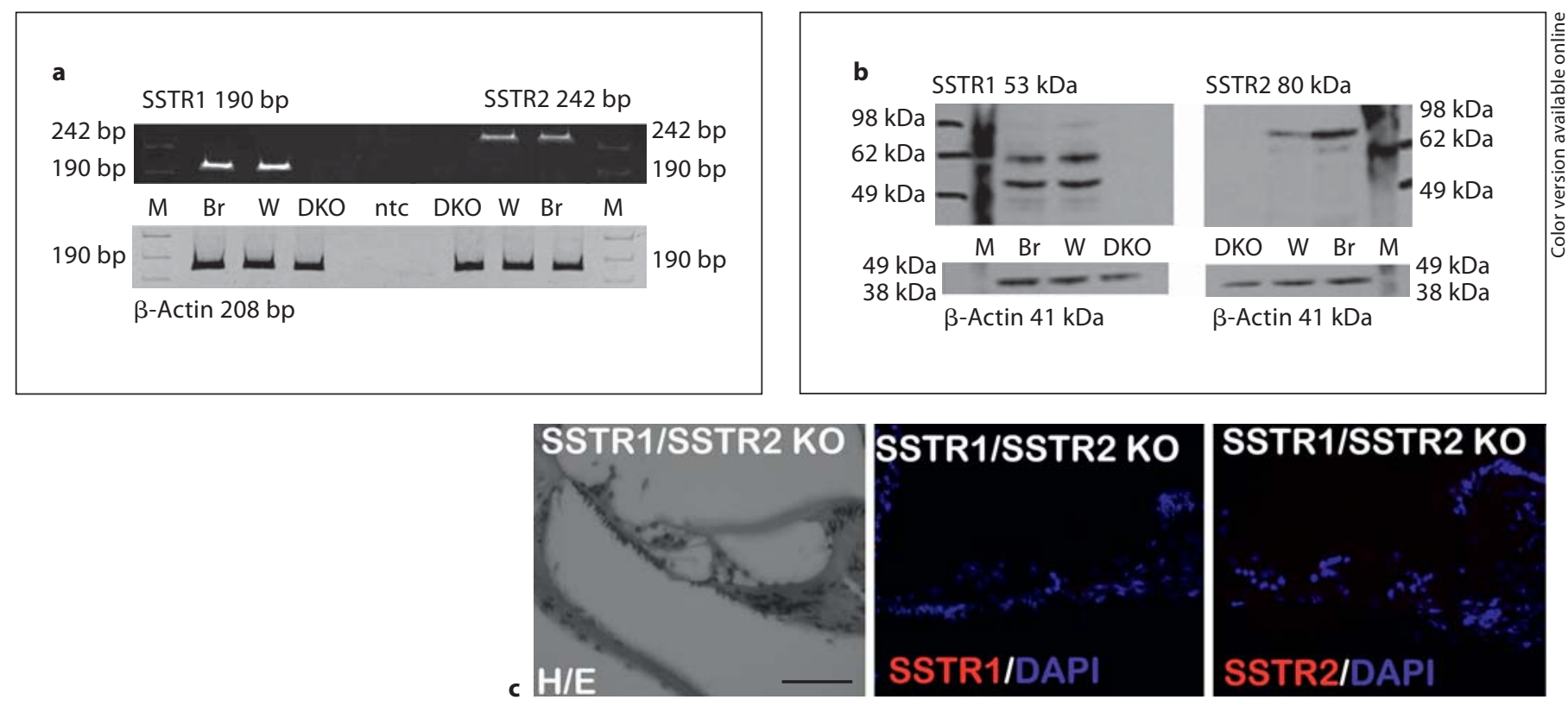

Fig. 8. SSTR1 and SSTR2 are not detected in SSTR1/SSTR2 DKO mice. a RT-PCR was performed on WT and DKO OC. SSTR1 and SSTR2 mRNA were detected in the OC from WT mice, but not in the OC from DKO mice. Brain (Br) RNA was used as a positive control. Omission of RT-PCR was used as the no-template control (ntc). $\beta$-Actin was used to control cDNA synthesis. b Western blotting reveals that SSTR1 and SSTR2 proteins can only be detected in protein extracts from brain tissue (positive control) and in OC extracts from WT mice, but not in the OC from DKO mice.
Actin serves as a standard to demonstrate that equal amounts of protein have been loaded. c Immunohistochemical detection of SSTR1 and SSTR2 protein in mouse cochlea. A light microscopy image of a mouse cochlea stained with hematoxylin/eosin to demonstrate that DKO cochleae have normal morphology. In the immunofluorescence images, SSTR1 and SSTR2 proteins cannot be detected in DKO cochleae. Cell nuclei are blue; SSTR1 and SSTR2 are red. Scale bars $=50 \mu \mathrm{m} . \mathrm{M}=$ Molecular weight marker; $\mathrm{W}=$ wild-type mice. 

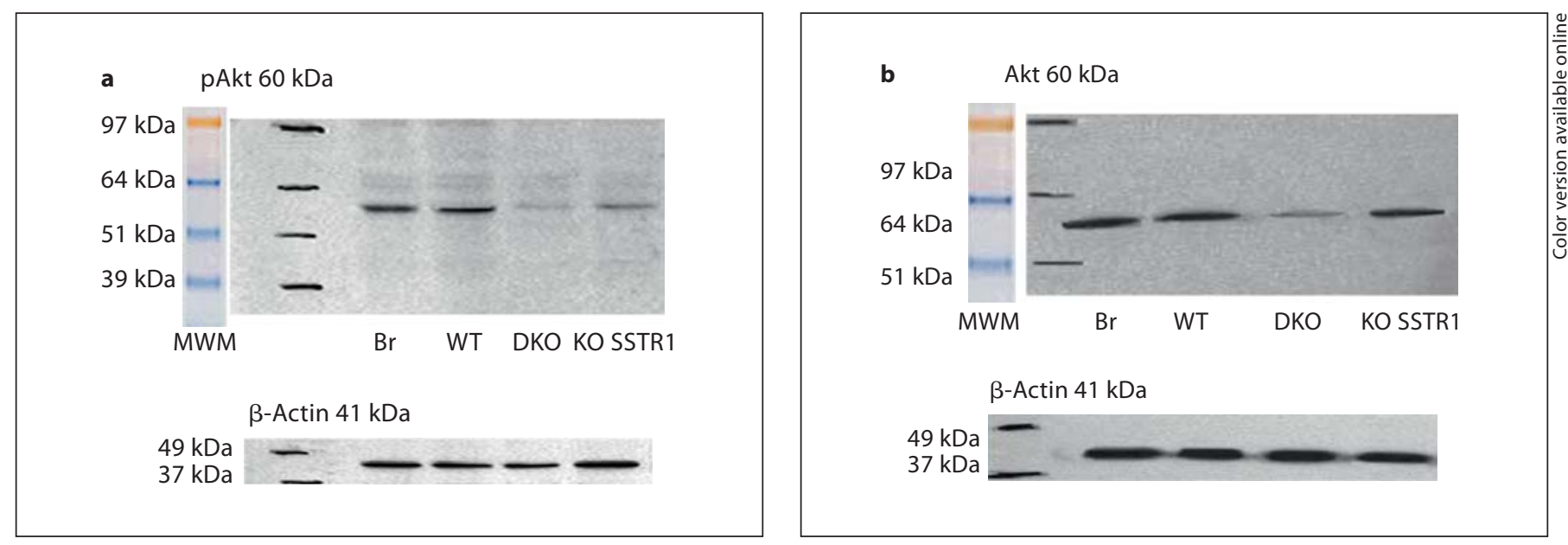

Fig. 9. Total Akt and phospho-Akt were detected in the OC and brains of SSTR1 KO and DKO mice. Levels of both phospho-Akt and total Akt were reduced in SSTR1 KO and DKO mice compared with WT littermates. Brain was used as a positive control, and $\beta$-actin levels were used as loading controls. $\mathrm{MWM}=$ Molecular weight marker.

phospho-Akt and total Akt in both strains of KO mice compared with WT mice (fig. 9b). Phospho-Akt and total Akt expression was lower in DKO mice than in SSTR1 KO mice (fig. 9). $\beta$-Actin was used as a loading control.

\section{Discussion}

The mRNA expression of SST and its receptor has been described in the developing mammalian central nervous system [31]. However, little is known about the presence of SSTR subtypes in the developing mammalian cochlea. The present study was undertaken to investigate the expression and the time course of SSTR1 and SSTR2 in the cochlea of fetal and postnatal mice. We analyzed these two individual SSTR subtypes using three independent techniques: mRNA analysis using RT-PCR and realtime PCR, and protein analysis using immunohistochemistry and Western blotting.

During maturation of the hearing organ, SSTR1 and SSTR2 were expressed in cochlea during late embryonic development. SSTR1- and SSTR2-positive cells can be observed in fetal mice as early as E14, and become present in all principal neurosensory cochlear cells before birth. The immunoreactivity of both receptors increases until approximately P14 (when maximal labeling of the IHC, $\mathrm{OHC}$, and supporting cells is reached for both receptors), and subsequently decreases by P21.

\section{Late Embryonic SSTR1 and SSTR2 Expression}

At E14, the receptors were expressed at the thickened epithelial cells located in the embryonic KlO. In mice, the cochlear duct develops from the otocyst at approximately E11 [2], and by E12 the growing duct becomes obvious as it begins to coil. By E17, HCs and supporting cells along the length of $\mathrm{KlO}$ have become arranged into the characteristic pattern for the OC [32]. Cochlear extension and coiling will continue until approximately E19-P0. During this period of development, the expression of both receptors increased and continued throughout the maturation of OC. We hypothesize that the high expression of both receptors at E17 supports the differentiation of the neuroepithelial cells in the embryonic OC, as well as general growth and development of the inner ear.

\section{STTR1 and SSTR2 Expression around the Onset of Hearing (P0-P14)}

The next peak of receptor expression occurs at P14 at the onset of hearing. SST is also known to modify the synapses, and is likely to influence the synaptic activity of the inner ear at P14 [33-35]. Like other rodent species, mice do not respond to airborne sound shortly after birth. The outer ear canal remains closed until P12, and auditory brainstem responses cannot be reliably recorded before P12-P14 [36-38]. High levels of both SSTR1 and SSTR2 proteins are expressed at P14, and were detected in supporting cells around the IHC, with weaker expression in the OHC. The increase of these proteins until P14 
may be necessary for the growth and development of the $\mathrm{OC}$, although not for mature hearing. Interestingly, there is a strong correlation of mRNA and protein levels for both receptors, suggesting that SSTR expression in the inner ear is controlled at the transcriptional level. In addition, it is noteworthy that the developmental pattern of SSTR1 and SSTR2 expression are similar. In our previous publication we observed that deletion of one receptor subtype was compensated by an overexpression of the other receptor subtype [25]. These findings support the idea that both receptors have a related function in the inner ear.

After P14, major anatomical structures and connections are already present. The expression of SSTR1 and SSTR2 at P21 is decreased relative to P14. From P21 onwards, SSTR1 and SSTR2 were concentrated in the OHC, IHC, and their supporting cells. The distribution patterns of SSTR1 and SSTR2 at P21 were similar to those observed in adult mice after airborne hearing ability had commenced. In our previous study, we demonstrated that, in the adult cochlea, SSTR1 and SSTR2 are expressed in the IHC and OHC of the OC, as well as in defined supporting cells [25].

According to different studies we know that the development of the nervous system requires the coordinated expression of many complex factors, in which SST seems to play an active role. From brain studies it is suggested that the SSTR1 and SSTR2 appear relatively early in the development. It has been suggested that during brain development SST may be involved in synaptogenesis, proliferation, axon pathfinding, and/or as a trophic factor $[39,40]$. The expression patterns of SSTR1 RNA in the hippocampus and SSTR2 as well as SSTR1 RNA in the cerebellum change significantly between E12 and P5. The temporal expression of the mRNAs coincides with the peak immunoreactivity found for SST by E18 and around the time of birth $[21,41]$. These results suggest that SSTR1 and SSTR2 are closely related to the neurogenesis of the hippocampus and cerebellum. SSTR1 and SSTR2 show high expression levels at E17. This may suggest that SSTR1 and SSTR2 serve as trophic factors and play a role in proliferation. Furthermore because of a high expression level of SSTR1 and SSTR2 at age P14 they may not only be involved in proliferation but also in synaptogenesis. There are 5 subtypes of SSTR (SSTR1-5). A possible explanation for the lack of dramatic effect on morphology of SSTR1/SSTR2 DKO mice is that the other subtypes (SSTR3-5) compensate for the absence of SSTR1 and SSTR2. Indeed, there is evidence that SST significantly contributes to the regulation of the expression of its re-

Somatostatin Receptors 1 and 2 in the Developing Cochlea ceptors (especially for the SSTR2 [42]). Furthermore, in SST KO and SSTR1 KO mice, brain levels of SSTR, and in particular of the SSTR2, are upregulated [43]. No morphological evidence was found by the lack of SSTR1 and SSTR2 expression in the central nervous system region of KO mice [29, 43-46].

\section{Protecting the Inner Ear}

The retina and ear share common characteristics. Both the retina and the inner ear arise from neuroepithelium, and both harbor sensitive sensory cells together with supporting cells. Both organs display a complex and highly organized microarchitecture. Therefore, the molecular events involved in damage and death of HCs might also share similar features to those involved in retinal cell damage and death $[47,48]$. Some aspects of the developmental patterns of the somatostatinergic system in the retina, including early SST expression, the presence of transient expressing ganglion cells, and observations in SSTR KO mice, clearly indicate that this peptide has a variety of roles in retinal development [49-53]. Moreover, SSTR 2 activation by SST or its analogues can protect retinal neurons against ischemia-induced damage [13], and studies in mice with genetic alterations of the somatostatinergic system have revealed that an increased presence of functional SSTR2 protects against retinal ischemia [54]. Therefore, SSTR2 analogues may be of therapeutic benefit in retinal diseases such as glaucoma or diabetic retinopathy, but may also protect from hearing loss due to $\mathrm{HC}$ degeneration and death. Research suggests that SST is involved in cell survival. In mouse retinal explants, SSTR2 has been shown to inhibit potassium-induced glutamate excitotoxicity [34]. Gentamicin and cisplatin are widely used pharmacological agents that may induce irreversible hearing loss. Both drugs damage mainly HCs, resulting in apoptotic HCs death $[55,56]$. Our group has demonstrated that SST can protect against aminoglycoside toxicity in a dosage-dependent manner in vitro [57]. Therefore, we hypothesized that the somatostatinergic system within the cochlea may have neuroprotective properties. These receptors may be employed as therapeutic agents to treat damage to and/or illness of the auditory system. Identification and characterization of the receptors and knowledge of peptide functions in cochlear development could enable us to design a peptide-based therapeutic strategy. Gentamicin exposure also activates pathways that promote $\mathrm{HC}$ survival in agreement with the current opinion that cells exist in a finely tuned balance between survival and cell death [58-60]. Some survival pathways that operate in 
HCs, such as the H-Ras/Raf/MEK/Erk pathway and the PI3K-Akt pathway, have been defined [61]. An interesting publication by Chung et al. [58] demonstrated that PI3K/Akt mediates HC survival and opposes gentamicin toxicity in neonatal rat OC explants. We therefore asked whether the observed protection from gentamicin by SST might be due to the influence of SST on the PI3K/ Akt pathway. There are some reports in the literature linking SST on the PI3K/Akt pathway. Furthermore, the activity of the PI3K/Akt pathway was altered by SST in pituitary tumor cells [38], and we have recently shown that the PI3K/Akt pathway is involved in NF-кB-dependent HC survival [39]. Indeed, data collected from our analysis of levels of phospho-Akt and total Akt protein in WT, SSTR1 KO, and DKO mice demonstrated that deletion of the receptors results in reduced levels of phospho-Akt and total Akt in the KO mice compared with WT mice (fig. 8). Therefore, we can speculate that the protection observed by SST on gentamicin-induced HC loss is due to the influence of SST at the PI3K/Akt pathway. Another possibility might be that SST protects HCs from aminoglycoside toxicity-induced cell death by its ability to limit glutamate release or to inhibit glutamate excitotoxicity, which has already been observed in the retina [34].
One family of growth factors, the neurotrophins, plays diverse roles in the survival of cochlear neurons. HCs are thought to secrete bone-derived neurotrophic factor and/ or neurotrophin-3 and attract nerve fibers to form synapses $[40,41]$. These developmental and protective functions also apply to SST.

Finally, future investigations in the development of the inner ear should concentrate on the time at which airborne hearing ability commences. A peak in the expression of certain receptors is observed at this time, when the auditory pathways have achieved their final organization, suggesting that SST and its receptors may operate (or cooperate) during cochlear development. Additional studies are needed to clarify to what extent SSTR play an essential role during the development of cochlear neural structures, and which transduction mechanisms are involved given the activation of specific SSTR subtypes.

\section{Acknowledgments}

The authors thank Prof. Konstantin Beier for help and support with the paraffin-sectioning procedures, Markus Saxer and Dr. Mirko Vukcevic for technical help, and Prof. Kapfhammer for comments on the manuscript. The Schwerhörigenverein Nordwestschweiz supported this work.

\section{References}

1 Fekete DM, Muthukumar S, Karagogeos D: Hair cells and supporting cells share a common progenitor in the avian inner ear. J Neurosci 1998;18:7811-7821.

2 Morsli H, Choo D, Ryan A, Johnson R, Wu DK: Development of the mouse inner ear and origin of its sensory organs. J Neurosci 1998; 18:3327-3335.

3 Brooker R, Hozumi K, Lewis J: Notch ligands with contrasting functions: Jagged 1 and Deltal in the mouse inner ear. Development 2006;133:1277-1286.

4 Kiernan AE, Xu J, Gridley T: The Notch ligand JAG1 is required for sensory progenitor development in the mammalian inner ear. PLoS Genet 2006;2:e4.

5 Zine A, Aubert A, Qiu J, Therianos S, Guillemot F, Kageyama R, de Ribaupierre F: Hes1 and Hes 5 activities are required for the normal development of the hair cells in the mammalian inner ear. J Neurosci 2001;21: 4712-4720.

-6 Shailam R, Lanford PJ, Dolinsky CM, Norton CR, Gridley T, Kelley MW: Expression of proneural and neurogenic genes in the embryonic mammalian vestibular system. J Neurocytol 1999;28:809-819.
7 Lanford PJ, Shailam R, Norton CR, Gridley T, Kelley MW: Expression of Math1 and HES5 in the cochleae of wild-type and Jag2 mutant mice. J Assoc Res Otolaryngol 2000; 1:161-171.

8 Patel YC: Somatostatin and its receptor family. Front Neuroendocrinol 1999;20:157-198.

-9 Epelbaum J, Dournaud P, Fodor M, Viollet C: The neurobiology of somatostatin. Crit Rev Neurobiol 1994;8:25-44.

10 Reisine T: Somatostatin receptors. Am J Physiol 1995;269:G813-G820.

-11 Fujii Y, Gonoi T, Yamada Y, Chihara K, Inagaki N, Seino S: Somatostatin receptor subtype SSTR2 mediates the inhibition of highvoltage-activated calcium channels by somatostatin and its analogue SMS 201-995. FEBS Lett 1994;355:117-120.

12 Wang HL, Reisine T, Dichter M: Somatostatin-14 and somatostatin-28 inhibit calcium currents in rat neocortical neurons. Neuroscience 1990;38:335-342.

13 Celiker U, Ilhan N: Nitric oxide and octreotide in retinal ischemia-reperfusion injury. Doc Ophthalmol 2002;105:327-338.
14 Theodoropoulou M, Zhang J, Laupheimer S, Paez-Pereda M, Erneux C, Florio T, Pagotto U, Stalla GK: Octreotide, a somatostatin analogue, mediates its antiproliferative action in pituitary tumor cells by altering phosphatidylinositol 3-kinase signaling and inducing Zacl expression. Cancer Res 2006;66: 1576-1582.

15 Moreno A, Akcakanat A, Munsell MF, Soni A, Yao JC, Meric-Bernstam F: Antitumor activity of rapamycin and octreotide as single agents or in combination in neuroendocrine tumors. Endocr Relat Cancer 2008;15:257266.

16 Cheng AG, Cunningham LL, Rubel EW: Mechanisms of hair cell death and protection. Curr Opin Otolaryngol Head Neck Surg 2009;135:1015-1018.

17 Nagy I, Caelers A, Monge A, Bonabi S, Huber AM, Bodmer D: NF-kappaB-dependent apoptotic hair cell death in the auditory system. Audiol Neurootol 2007;12:209-220.

18 Bulloch AG: Somatostatin enhances neurite outgrowth and electrical coupling of regenerating neurons in Helisoma. Brain Res 1987; 412:6-17. 
19 Bagnoli P, Dal Monte M, Casini G: Expression of neuropeptides and their receptors in the developing retina of mammals. Histol Histopathol 2003;18:1219-1242.

-20 Viollet C, Bodenant C, Prunotto C, Roosterman D, Schaefer J, Meyerhof W, Epelbaum J, Vaudry H, Leroux P: Differential expression of multiple somatostatin receptors in the rat cerebellum during development. J Neurochem 1997;68:2263-2272.

-21 Naus CC, Bloom FE: Immunohistochemical analysis of the development of somatostatin in the reeler neocortex. Brain Res 1988;471: 61-68.

22 Ferriero DM, Sheldon RA, Messing RO: Somatostatin enhances nerve growth factorinduced neurite outgrowth in PC12 cells. Brain Res Dev Brain Res 1994;80:13-18.

23 Kungel M, Friauf E: Somatostatin and leuenkephalin in the rat auditory brainstem during fetal and postnatal development. Anat Embryol (Berl) 1995;191:425-443.

-24 Taniwaki T, Schwartz JP: Somatostatin enhances neurofilament expression and neurite outgrowth in cultured rat cerebellar granule cells. Brain Res Dev Brain Res 1995; 88:109-116.

-25 Radojevic V, Hanusek C, Setz C, Brand Y, Kapfhammer JP, Bodmer D: The somatostatinergic system in the mammalian cochlea. BMC Neurosci 2011;12:89.

26 Kandler K, Friauf E: Pre- and postnatal development of efferent connections of the cochlear nucleus in the rat. J Comp Neurol 1993;328:161-184.

27 Sanes DH, Siverls V: Development and specificity of inhibitory terminal arborizations in the central nervous system. J Neurobiol 1991;22:837-854.

28 Feldman SC, Harris MR, Laemle LK: The maturation of the somatostatin systems in the rat visual cortex. Peptides 1990;11:10551064.

-29 Kreienkamp HJ, Akgun E, Baumeister H, Meyerhof W, Richter D: Somatostatin receptor subtype 1 modulates basal inhibition of growth hormone release in somatotrophs. FEBS Lett 1999;462:464-466.

- 30 Zheng H, Bailey A, Jiang MH, Honda K, Chen HY, Trumbauer ME, Van der Ploeg LH, Schaeffer JM, Leng G, Smith RG: Somatostatin receptor subtype 2 knockout mice are refractory to growth hormone-negative feedback on arcuate neurons. Mol Endocrinol 1997;11:1709-1717.

-31 Epelbaum J: Somatostatin in the central nervous system: physiology and pathological modifications. Prog Neurobiol 1986;27:63100.

32 Kelley MW: Cellular commitment and differentiation in the organ of Corti. Int J Dev Biol 2007;51:571-583.

33 Kaneko S, Maeda T, Satoh M: Cognitive enhancers and hippocampal long-term potentiation in vitro. Behav Brain Res 1997;83:4549.
34 Pilar G, Gray DB, Meriney SD: Membrane delimited and intracellular soluble pathways in the somatostatin modulation of ACh release. Life Sci 1996;58:1979-1986.

35 Dalezios Y, Lujan R, Shigemoto R, Roberts JD, Somogyi P: Enrichment of mGluR7a in the presynaptic active zones of GABAergic and non-GABAergic terminals on interneurons in the rat somatosensory cortex. Cereb Cortex 2002;12:961-974.

36 Uziel A, Romand R, Marot M: Development of cochlear potentials in rats. Audiology 1981;20:89-100.

37 Blatchley BJ, Cooper WA, Coleman JR: Development of auditory brainstem response to tone pip stimuli in the rat. Brain Res 1987; 429:75-84.

38 Geal-Dor M, Freeman S, Li G, Sohmer H: Development of hearing in neonatal rats: air and bone conducted ABR thresholds. Hear Res 1993;69:236-242.

-39 Bodenant C, Leroux P, Gonzalez BJ, Vaudry $\mathrm{H}$ : Transient expression of somatostatin receptors in the rat visual system during development. Neuroscience 1991;41:595-606.

40 Bodenant C, Leroux P, Vaudry H: Localization of somatostatin receptors in subcortical visual centres of the rat during development. Effect of neonatal enucleation on the expression of somatostatin receptors. Neuroscience 1993;53:1097-1102.

41 Naus CC, Miller FD, Morrison JH, Bloom FE: Immunohistochemical and in situ hybridization analysis of the development of the rat somatostatin-containing neocortical neuronal system. J Comp Neurol 1988;269: 448-463.

42 Csaba Z, Richichi C, Bernard V, Epelbaum J, Vezzani A, Dournaud P: Plasticity of somatostatin and somatostatin sst2A receptors in the rat dentate gyrus during kindling epileptogenesis. Eur J Neurosci 2004;19:25312538.

43 Ramirez JL, Mouchantaf R, Kumar U, Otero Corchon V, Rubinstein M, Low MJ, Patel YC: Brain somatostatin receptors are up-regulated in somatostatin-deficient mice. Mol Endocrinol 2002;16:1951-1963.

44 Cammalleri M, Cervia D, Dal Monte M, Martini D, Langenegger D, Fehlmann D, Feuerbach D, Pavan B, Hoyer D, Bagnoli P: Compensatory changes in the hippocampus of somatostatin knockout mice: upregulation of somatostatin receptor 2 and its function in the control of bursting activity and synaptic transmission. Eur J Neurosci 2006; 23:2404-2422.

45 Zeyda T, Diehl N, Paylor R, Brennan MB, Hochgeschwender U: Impairment in motor learning of somatostatin null mutant mice. Brain Res 2001;906:107-114.
46 Dal Monte M, Petrucci C, Vasilaki A, Cervia D, Grouselle D, Epelbaum J, Kreienkamp HJ, Richter D, Hoyer D, Bagnoli P: Genetic deletion of somatostatin receptor 1 alters somatostatinergic transmission in the mouse retina. Neuropharmacology 2003;45:10801092.

47 Casini G, Catalani E, Dal Monte M, Bagnoli $P$ : Functional aspects of the somatostatinergic system in the retina and the potential therapeutic role of somatostatin in retinal disease. Histol Histopathol 2005;20:615-632.

48 Mastrodimou N, Lambrou GN, Thermos K: Effect of somatostatin analogues on chemically induced ischaemia in the rat retina. Naunyn Schmiedebergs Arch Pharmacol 2005;371:44-53.

49 Ferriero DM: Developmental expression of somatostatin receptors in the rat retina. Brain Res Dev Brain Res 1992;67:309-315.

50 Ferriero DM, Sagar SM: Development of somatostatin immunoreactive neurons in rat retina. Brain Res 1987;431:207-214

-51 Ferriero DM, Head VA, Edwards RH, Sagar SM: Somatostatin mRNA and molecular forms during development of the rat retina. Brain Res Dev Brain Res 1990;57:1519.

52 Fontanesi G, Casini G, Thanos S, Bagnoli P: Transient somatostatin-immunoreactive ganglion cells in the developing rat retina. Brain Res Dev Brain Res 1997;103:119-125.

53 Casini G: Neuropeptides and retinal development. Arch Ital Biol 2005;143:191-198.

54 Catalani E, Cervia D, Martini D, Bagnoli P, Simonetti E, Timperio AM, Casini G: Changes in neuronal response to ischemia in retinas with genetic alterations of somatostatin receptor expression. Eur J Neurosci 2007; 25:1447-1459.

55 Dulon D, Zajic G, Aran JM, Schacht J: Aminoglycoside antibiotics impair calcium entry but not viability and motility in isolated cochlear outer hair cells. J Neurosci Res 1989; 24:338-346.

56 Kroese AB, van den Bercken J: Effects of ototoxic antibiotics on sensory hair cell functioning. Hear Res 1982;6:183-197.

57 Caelers A, Monge A, Brand Y, Bodmer D: Somatostatin and gentamicin-induced auditory hair cell loss. Laryngoscope 2009;119: 933-937.

58 Chung WH, Pak K, Lin B, Webster N, Ryan AF: A PI3K pathway mediates hair cell survival and opposes gentamicin toxicity in neonatal rat organ of Corti. J Assoc Res Otolaryngol 2006;7:373-382.

59 Boatright KM, Salvesen GS: Caspase activation. Biochem Soc Symp 2003;70:233-242.

60 Boatright KM, Salvesen GS: Mechanisms of caspase activation. Curr Opin Cell Biol 2003; 15:725-731.

61 Battaglia AA, Sehayek K, Grist J, McMahon SB, Gavazzi I: EphB receptors and ephrin-B ligands regulate spinal sensory connectivity and modulate pain processing. Nat Neurosci 2003;6:339-340. 